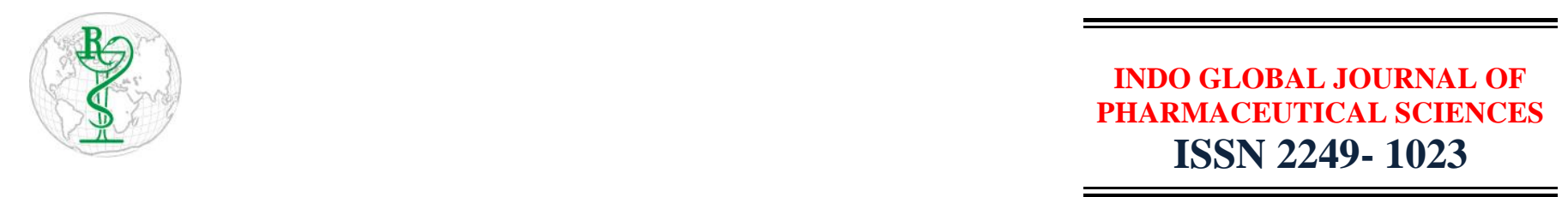

\title{
O-Pentyne and Morpholine/Piperidine Ethyl Substituted Pyrimidines as Anti-Alzheimer's Agents
}

\author{
Devashish Mehta, Vijay Kumar, Vinod Kumar * \\ Department of Pharmaceutical Sciences and Natural Products, Central University of Punjab, Bathinda 151001 \\ Address for Correspondence: Vinod Kumar; devashishmehta7754@gmail.com
}

Received:

01.03.2019

Accepted:

25.03.2019

Keywords

Alzheimer's

Disease; Multi-

Targeted

Compounds.
ABSTRACT: Alzheimer's disease (AD) is an irreversible neurodegenerative disorder. It is characterized by the impairment in memory and cognitive dysfunctioning. The neuropathological hallmarks of AD are decreased acetylcholine (Ach) levels in brain, increased reactive oxygen species (ROS) and deposition of amyloid beta. The exact pathogenesis of $\mathrm{AD}$ is still not clear. In $\mathrm{AD}$ there is hyperactivity of acetylcholinesterase (AchE) and monoamine oxidase -B (MAO-B), which leads to decreased Ach and increased ROS levels respectively. So, AchE and MAO-B are the potential therapeutic targets for the treatment of AD. Simultaneous inhibition of these target enzymes with a single molecule can be a beneficial therapeutic strategy. A total of 9 multi-targeted compounds are designed and synthesized using hybrid molecular approach and two pharmacophores are incorporated on the pyrimidine nucleus. The in-silico studies of these compounds revealed that the compound DEV-28possess potent AchE and MAO-B inhibitory properties. (C) 2019 iGlobal Research and Publishing Foundation. All rights reserved.

Cite this article as: Mehta, D.; Kumar, V.; Kumar, V. O-Pentyne and morpholine/piperidine ethyl substituted pyrimidines as anti-alzheimer's agents. Indo Global J. Pharm. Sci., 2019; 9(2Suppl.): 116. DOI: http://doi.org/10.35652/IGJPS.2019.92S14 .

Indo Global Journal of Pharmaceutical Sciences( ISSN 2249 1023; CODEN- IGJPAI; NLM ID: 101610675) indexed and abstracted in CrossRef (DOI Enabling), UGC CARE Journal List, EMBASE(Elsevier), National Library of Medicine (NLM) Catalog, ResearchGate, Publons, CAS (ACS), Index Copernicus, Google Scholar and many more. For further details, visit http://iglobaljournal.com

This is a special issue as an outcome of 'RAPSCON-2019' sponsored by APTI and organized by Sri Sai College of Pharmacy, Manawala, Amritsar, Punjab, India. Relaxation offered in journal format. 